\title{
Antioxidant properties of HDL
}

\author{
Handrean Soran ${ }^{1,2}$, Jonathan D. Schofield ${ }^{1,2}$ and Paul N. Durrington ${ }^{1 *}$ \\ ${ }^{1}$ Cardiovascular Research Group, Core Technology Facility, University of Manchester, Manchester, UK, ${ }^{2}$ Cardiovascular Trials \\ Unit, Central Manchester University Hospitals NHS Foundation Trust, Manchester, UK
}

High-density lipoprotein (HDL) provides a pathway for the passage of lipid peroxides and lysophospholipids to the liver via hepatic scavenger receptors. Perhaps more importantly, HDL actually metabolizes lipid hydroperoxides preventing their accumulation on low-density lipoprotein (LDL), thus impeding its atherogenic structural modification. A number of candidates have been suggested to be responsible for HDL's antioxidant function, with paraoxonase-1 (PON1) perhaps the most prominent. Here we review the evidence for HDL anti-oxidative function and the potential contributions of apolipoproteins, lipid transfer proteins, paraoxonases and other enzymes associated with HDL.

\section{OPEN ACCESS}

Edited by:

Norman Eric Miller,

University of Oxford, UK

Reviewed by:

Giovanna Cenini

Universität Bonn, Germany

Ghanshyam Upadhyay,

City College of New York, USA

*Correspondence:

Paul N. Durrington,

Cardiovascular Research Group, Core Technology Facility, University of Manchester, 3rd Floor, 46 Grafton Street, Manchester M13 9NT, UK pdurrington@manchester.ac.uk

Specialty section:

This article was submitted to Experimental Pharmacology and Drug

Discovery,

a section of the journal

Frontiers in Pharmacology

Received: 25 June 2015 Accepted: 17 September 2015 Published: 16 October 2015

Citation:

Soran H, Schofield JD and Durrington PN (2015) Antioxidant properties of HDL.

Front. Pharmacol. 6:222. doi: 10.3389/fphar.2015.00222
Keywords: apolipoprotein A1, glycated low-density lipoprotein, high-density lipoprotein, oxidized low-density lipoprotein, paraoxonase 1

\section{Introduction}

Whilst atherogenesis is a complex process, macrophage-derived foam cell formation resulting from the uptake of circulating low-density lipoprotein (LDL) is of fundamental importance. Despite this, foam cell formation with LDL is impossible to instigate in vitro due to insufficient monocytemacrophage LDL receptor expression (Steinberg and Witztum, 2010). It was, however, discovered that experimental chemical modification of LDL permitted its rapid receptor-mediated uptake by monocyte-macrophages to form foam cells. This led to the identification of the scavenger receptors (Stocker and Keaney, 2004; Steinberg and Witztum, 2010) and opened new avenues of research to identify possible in vivo atherogenic modifications of LDL. Oxidation, glycation, and homocysteinylation have all been explored. Although, clinical trials of chain-breaking antioxidants proved disappointing in the prevention of atherosclerotic cardiovascular disease (Heart Protection Study Collaborative, 2002), other systems which might oppose potentially atherogenic LDL modifications, including high-density lipoprotein (HDL) merit further attention.

We have contributed to the notion that paraoxonase 1 (PON1), an enzyme located almost exclusively on HDL, is important in impeding oxidative modification of LDL (Mackness et al., 1991, 1993; Durrington et al., 2001). Our recent work has focused on glycation as an atherogenic modification of LDL and this too has led us back to PON1 (Younis et al., 2013). Other HDL components have also been conjectured to be involved in preventing atherogenic LDL modification and evidence increasingly points to a coordination of these with PON1. Understanding these protective mechanisms might reveal important pathways which could be manipulated therapeutically to prevent atherosclerosis.

\section{Atherogenic LDL Modification}

The discovery that chemical modification of LDL by acetylation increases its affinity for macrophage scavenger receptors and reduces binding to the physiological LDL receptor led to 
a search for naturally occurring modifications which might have similar effects (Steinberg and Witztum, 2010). The ensuing hypothesis that lipid peroxidation products produced on LDL when subjected to attack by oxygen free radicals are responsible for changes in the apolipoprotein B100 (apoB) of LDL which alter its receptor binding preferences remains compelling despite the disappointing lack of effect of chain-breaking antioxidants (Heart Protection Study Collaborative, 2002; Stocker and Keaney, 2004; Steinberg and Witztum, 2010). Perhaps unsurprisingly given the safeguards against oxygen free radical damage, oxidized LDL is only found at low circulating concentrations, although it has been argued that higher levels might occur at sites where LDL is sequestered and this might include the arterial wall (Stocker and Keaney, 2004).

We were surprised to discover that glycated apoB was present in the circulation at relatively high concentrations of around $2-3 \mathrm{mg} / \mathrm{dl}$ in healthy people and at higher levels in diabetes and in hypercholesterolaemia (Tames et al., 1992). This has been confirmed by immunoassays detecting epitopes unique to glycated LDL and we have also shown that atherogenic small dense LDL is more heavily glycated than other LDL subfractions in vivo, and is more susceptible to glycation in vitro (Younis et al., 2009, 2010). Glycated LDL also has a longer circulating half-life than unmodified LDL, and is removed from the circulation by route(s) not involving the LDL receptor. Interestingly, statins also reduce circulating concentrations, likely by reducing LDL available to undergo glycation (Younis et al., 2010).

Homocysteine may also be atherogenic; thiolation of LDL free amino groups by homocysteine thiolactone increases its uptake by macrophages (McCully, 1993). Interestingly the lactonase activity of PON1 will detoxify homocysteine thiolactone in addition to its role in preventing LDL oxidation (see later).

\section{HDL Antioxidative Activity}

Lipid hydroperoxides formed on LDL will migrate to its surface as a result of their greater hydrophilicity, facilitating their transfer to HDL (Parthasarathy et al., 1990). This transfer can occur directly between lipoprotein phospholipid monolayers, but may be assisted by lipid transfer proteins (see Figure 1). HDL might thus provide a pathway for the passage of lipid peroxides and lysophospholipids to the liver via hepatic scavenger receptors. Perhaps more importantly, HDL actually metabolizes lipid hydroperoxides preventing their accumulation, consequently impeding the atherogenic structural modification of LDL (Mackness et al., 1991). We have observed that when HDL is incubated with LDL under oxidizing conditions the accumulation of lipid peroxides on LDL is decreased, but the concentration of lipid peroxides on HDL remains similar to that observed when HDL alone is oxidized (Mackness et al., 1991, 1993). This effect of HDL is obvious within $3 \mathrm{~h}$, by which time typically more than $50 \%$ of the lipid peroxidation of LDL which would occur in the absence of HDL has been prevented. These results suggest that this effect is related to enzymatic activity associated with HDL, and not chain-breaking antioxidants or transition metal chelation (Mackness et al., 1993; Durrington et al., 2001). It should also be noted that this anti-oxidative function of HDL is observed in vitro with similar protein concentrations of LDL and HDL; greater suppression of LDL oxidation might be expected when HDL concentrations exceed those of LDL as they do in the interstitial fluid. In fact, the accumulation of oxidized lipids in HDL likely results not only from their transfer from LDL but also from triglyceride-rich remnant particles and endothelial cells. The antioxidant effects of HDL are now well established and have been demonstrated in a number of experimental systems (Kontush and Chapman, 2010).

\section{HDL Antiglycative Activity}

We have also shown that HDL can impede the modification of LDL by glycation in vitro, and that this anti-glycative function of HDL is more marked with HDL obtained from people with higher serum PON1 activity (Younis et al., 2013). We noted in these experiments that LDL is relatively resistant to glycation in the absence of oxygen, such that supraphysiological glucose concentrations are required. Oxidation appears to accompany in vitro glycation and the process is best regarded as glycoxidation. The lipid peroxidation of LDL that accompanies in vitro glycation is also impeded in the presence of HDL. Adduction of lipid peroxidation products to the $\varepsilon$ amino groups of apoB lysine residues in vivo may render these groups more susceptible to combination with glucose. Thus, in vivo exposure of LDL to oxygen free radicals may predispose to glycation and explain the observed high levels of circulating glycated LDL. The effect of HDL on glycation may thus be related to its anti-oxidative function. An alternative hypothesis is that the oxidized analog of glucose, gluconolactone, is more involved in apoB glycation, and that this step might be affected by PON1's lactonase activity.

\section{Paraoxonase 1}

PON1 is produced in the liver and circulates on HDL. There is a significant body of evidence to support a role for PON1 in atherosclerosis, and in particular against oxidation, not least its capacity to hydrolyze lipid hydroperoxides.

We demonstrated that the HDL fraction containing PON1 was most active in impeding $\mathrm{Cu}^{2+}$ induced lipid peroxide accumulation on LDL (Mackness et al., 1993). It has since been suggested that it is not PON1 which is responsible for this effect, an argument supported by reports that more highly purified PON1 isolated from HDL and recombinant watersoluble variants of PON1 do not hydrolyze lipid peroxides (Draganov et al., 2005; Kontush and Chapman, 2010). It is however exceptionally difficult to separate PON1 from other HDL components, such as apolipoprotein AI (apoAI) and phospholipase A2 (PLA2), without subjecting it to conditions which might affect its catalytic activity (Ben-David et al., 2015). Similarly, the increased polarity of recombinant PON1 would be expected to compromise its ability to hydrolyze hydrophobic substrates (Harel et al., 2004; Draganov et al., 2005; Bajaj et al., 2014). More lipophilic recombinant PON1 might be expected to have improved functionality, but is more difficult to isolate, a factor which will prove important in the development of 


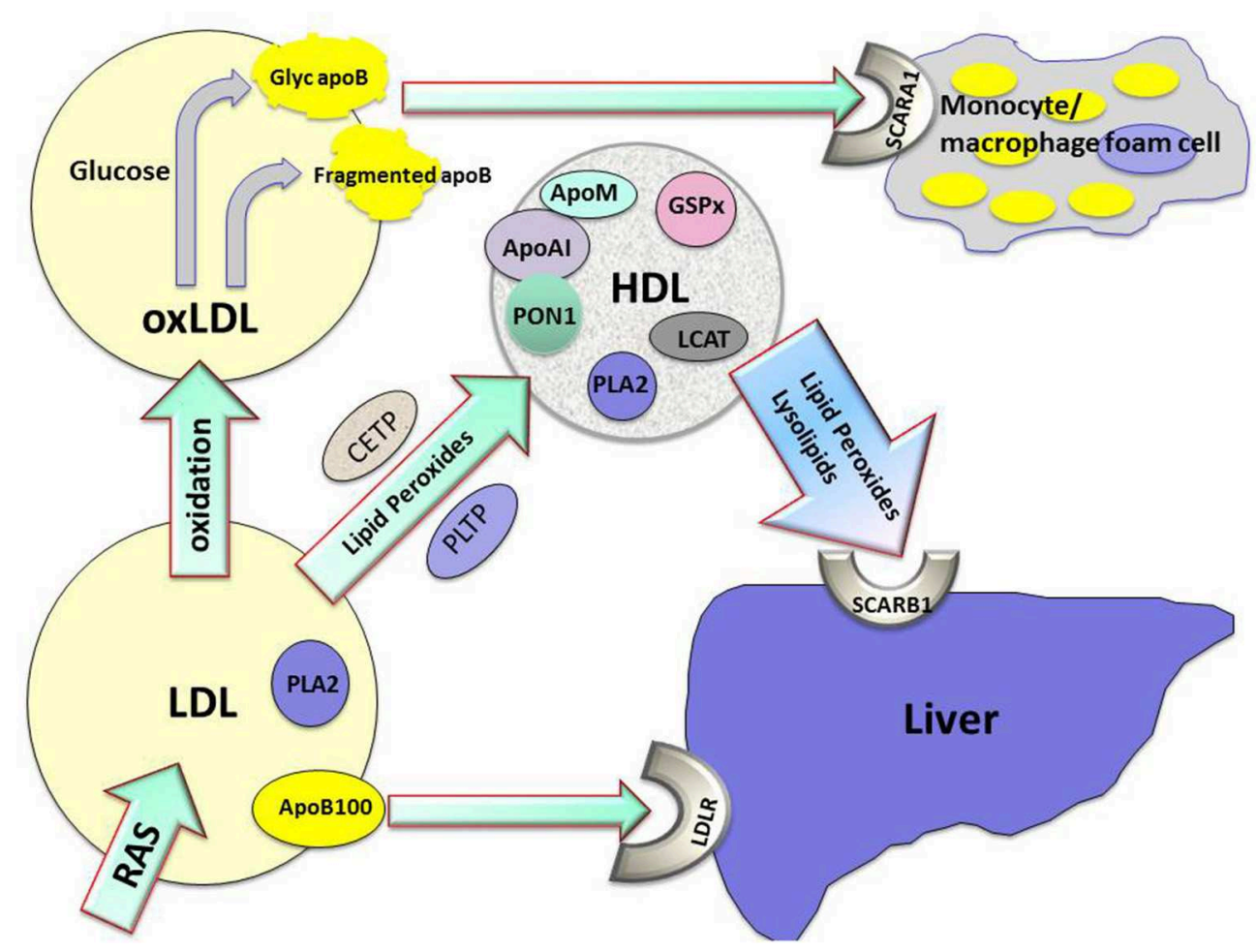

FIGURE 1 | The role played by high density lipoprotein (HDL) in the metabolism of lipid hydroperoxides and lysolipids and protection against atherogenesis. Apo Al, apolipoprotein Al; apoB100, apolipoprotein B100; apoM, apolipoprotein M; CETP, cholesteryl ester transfer protein; glyc apoB, glycated apolipoprotein B; GSPx, glutathione peroxidase; LDL, low density lipoprotein; LDLR, low density lipoprotein receptor; oxLDL, oxidized low density lipoprotein; PLA2, phospholipase A2; PLTP, phospholipid transfer protein; PON1, paraoxonase1; RAS, reactive oxygen species; SCARA1, scavenger receptor A1; SCARB1, scavenger receptor B1.

recombinant PON1 for therapeutic use (Bajaj et al., 2014). Interestingly, HDL from avian species, which lacks paraoxonase activity, does not protect human LDL against lipid peroxidation (Mackness et al., 1998). Similarly, PON1 knockout mice are more susceptible to atherosclerosis and their HDL is less able to prevent the accumulation of lipid peroxides on human LDL (Shih et al., 1998), whereas transgenic rodent models expressing human PON1 are protected against atherosclerosis (Tward et al., 2002; Zhang et al., 2010).

Epidemiological studies have consistently shown that PON1 activity is independently inversely associated with coronary events (Mackness et al., 2003; Wang et al., 2012). A recent metaanalysis, which considered 47 such studies, reported that PON1 activity was $19 \%$ lower in patients suffering from coronary heart disease than in unaffected controls (Wang et al., 2012). Other prospective studies expanded on the negative correlation between PON1 activity and coronary heart disease by also reporting circulating levels of lipid peroxidation products, linking these to PON1 anti-oxidative activity (Bhattacharyya et al., 2008; Karlsson et al., 2015).

A number of medical conditions including diabetes mellitus, chronic kidney disease, familial hypercholesterolaemia and inflammatory arthritides are associated with both decreased serum PON1 activity and increased CVD risk (Soran et al., 2009). PON1 activity is decreased in both type 1 and 2 diabetes
(Mackness et al., 2000, 2002) and lower levels are associated with microvascular complications (Mackness et al., 2000, 2002; Hofer et al., 2006).

PON1 has several genetic polymorphisms, the most extensively researched of which is the R192Q variant. This polymorphism has a substantial effect on PON1's capacity to hydrolyze paraoxon and homozygotes and heterozygotes for the $\mathrm{R}$ allele are more resistant to parathion (paraoxon is formed from this widely used organophosphate pesticide once it enters the body) than QQ homozygotes (Mackness et al., 2001; Cherry et al., 2002; Wheeler et al., 2004). Other activities of PON1, such as phenyl acetate hydrolysis, which proceed at faster rates, are, however, unaffected by the R192Q polymorphism. In the case of the protective effect of HDL against LDL oxidation, HDL from 192QQ homozygotes is most effective in preventing the accumulation of lipid peroxides on LDL (Mackness et al., 1997; Durrington et al., 2001), but this effect is small in comparison to the huge variation in serum PON1 activity. Nonetheless 192QQ homozygotes have been reported to have reduced CVD risk (Mackness et al., 2001; Wheeler et al., 2004). This inverse association is, however, within the range which could be explained by publication bias, but it does not deny that the wider range of PON1 activities encountered in populations resulting from other genetic and acquired influences are relevant to the development of atherosclerosis. It certainly indicates that the 
substrate specificity involved in the antiatherogenic effect of PON1 is not greatly influenced by the R192Q polymorphism.

PON1 and PON2 genotype have been linked with susceptibility to develop diabetes (Rozenberg et al., 2008), glycaemic control (Hegele et al., 1997), and diabetic microvascular complications (Mackness et al., 2000; Hofer et al., 2006; Wang et al., 2013). It has been suggested that this association reflects a role for oxidation in pancreatic $\beta$ cell dysfunction or microvascular disease. Alternatively, it might reflect an ability of HDL / PON1 to prevent post-translational protein glycation.

Parenteral administration of partially purified PON1 can ameliorate experimental atherosclerosis. Recombinant PON1 might also be used for this purpose, if its properties can be retained during isolation (Draganov et al., 2005; Bajaj et al., 2014). Intraperitoneal injection of recombinant PON1 in mice increased cholesterol efflux capacity and HDL aryl esterase and lactonase activities, and decreased macrophage mediated LDL oxidation (Rosenblat et al., 2011).

\section{Paraoxonase 2 and Paraoxonase 3}

PON2 is almost exclusively found intracellularly, whereas PON3 is also associated with HDL, albeit in lesser quantities than PON1. The primary hydrolytic activity of PON3 is also as a lactonase (Draganov et al., 2005). PON3 knockout mice are also more susceptible to atherosclerosis (Zhang et al., 2010), but the reason for its evolutionary conservation is currently unclear.

\section{Apolipoprotein Al}

ApoAI is essential both for the structure of HDL and the maintenance of the lipid environment in which enzymes such as PON1 and lecithin: cholesterol acyl transferase (LCAT) can operate (Rye and Barter, 2014). It is therefore likely to have a major role in the antioxidant effects of HDL. ApoAI plays a central role in the redox inactivation of lipid hydroperoxides which follows their transfer to HDL. ApoAI also creates a safe environment for the release of lysophospholipids and their subsequent transfer to the liver. Despite experimental evidence that lipid-protein complexes containing only apoAI can protect LDL against oxidation (Karlsson et al., 2015), neither animal models nor human genetic disorders have provided convincing evidence that apoAI's anti-atherogenic effects are independent of changes in HDL levels (Duverger et al., 1996; Plump et al., 1997). Interestingly, apoAI-mimetic peptides create circulating lipid complexes, which associate with other components of HDL such as PON1 (Mishra et al., 2013). This may provide a means of enhancing circulating PON1 activity.

\section{Apolipoprotein All (apoAII)}

Apolipoprotein AII (apoAII)-containing HDL particles tend to be larger and possess less antioxidant activity than those with higher apoAI content (Karlsson et al., 2015). There is evidence from both animal models and human studies to suggest that apoAII might actually suppress PON1 binding to HDL (Litvinov et al., 2012). Mice expressing human apoAII and apoAI are more susceptible to atherosclerosis than those expressing apoAI alone.

\section{Other Apolipoproteins}

Other apolipoproteins associated with HDL may act alongside apoAI to inhibit lipid hydroperoxide accumulation. Apolipoprotein E (apoE) appears to display this anti-oxidative activity (Miyata and Smith, 1996), while apolipoprotein M (apoM) has recently been reported to display anti-oxidative functionality in transgenic mice in addition to facilitating PON1 activity (Elsøe et al., 2012; Borup et al., 2015). There is currently little evidence that apolipoprotein $\mathrm{J}$ (apoJ) contributes to the anti-oxidative activities of HDL, but it does appear to possess a variety of functions, including endothelial protection.

\section{Myeloperoxidase (MPO)}

Cellular systems contributing to oxidative stress in vivo include MPO, NADPH oxidase, nitric oxide synthase, and lipoxygenase (Karlsson et al., 2015). It has recently been proposed that MPO and PON1 form a ternary complex with HDL, where the opposing activities of MPO and PON1 determine its oxidation state and whether HDL is pro- or anti-inflammatory/atherogenic (Huang et al., 2013). The ratio between these enzyme activities has also been proposed as a marker of HDL functionality and to predict coronary risk (Haraguchi et al., 2014).

\section{Glutathione Peroxidase (GSPx)}

Although, its levels do not appear to affect coronary heart disease risk, GSPx is found associated with HDL, where it has the ability to reduce lipid hydroperoxides (Karlsson et al., 2015). Similarly, trypanosome lytic factor present in higher density HDL also exhibits peroxidase activity and may contribute to the anti-oxidative properties of HDL (Karlsson et al., 2015).

\section{Phospholipase A2}

Most PLA2 is associated with LDL, where its activity is an independent risk factor for coronary heart disease (Rosenson and Hurt-Camejo, 2012). There is however, no evidence that the minor fraction of PLA2 activity on HDL is pro-atherogenic. Furthermore, PLA2 has overlapping activity with PON1 and it remains unclear just how much of the hydrolysis of platelet activating factor by HDL is due to PLA2 and how much to PON1 (Rodrigo et al., 2001). PLA2 on HDL is likely to contribute anti-oxidative activity by the same mechanism as PON1, by hydrolyzing lipid hydroperoxides. This activity, which would be pro-atherogenic on LDL in the presence of apoB, may be antiatherogenic in the environment provided by HDL.

\section{Lecithin: Cholesterol Acyl Transferase}

Similarly, there is currently limited evidence to support a role for LCAT in the antioxidative activity of HDL (Holleboom et al., 2012), but its association with HDL and, like PON1 and PLA2, 
its role in generating lysophospholipids, does contribute to the hypothesis that HDL provides a safe place to release lysolipids otherwise potentially damaging to cell membranes and other lipoproteins.

\section{Cholesteryl Ester Transfer Protein (CETP) and Phospholipid Transfer Protein (PLTP)}

The antioxidant activity of HDL occurs following the transfer of lipid hydroperoxides to HDL. Experimentally no additional facilitator of transfer to HDL is required, but some CETP and PLTP are likely to remain in physical association with HDL after its isolation. CETP can accelerate the transfer of both cholesteryl ester and phospholipid hydroperoxides (Christison et al., 1995). CETP and/or PLTP may thus be important for the anti-oxidative effect of HDL in vivo. Like PON1, PLTP is found predominantly in small, dense HDL, where it is able to interact with apolipoproteins implicated in anti-oxidative function, including apoAI, apoAII, and apoJ (Karlsson et al., 2015).

\section{References}

Bajaj, P., Tripathy, R. K., Aggarwal, G., and Pande, A. H. (2014). Human paraoxonase 1 as a pharmacologic agent: limitations and perspectives. Sci. World J. 2014:854391. doi: 10.1155/2014/854391

Ben-David, M., Sussman, J. L., Maxwell, C. I., Szeler, K., Kamerlin, S. C., and Tawfik, D. S. (2015). Catalytic stimulation by restrained active-site floppinessthe case of high density lipoprotein-bound serum paraoxonase-1. J. Mol. Biol. 427(6 Pt B), 1359-1374. doi: 10.1016/j.jmb.2015.01.013

Bhattacharyya, T., Nicholls, S. J., Topol, E. J., Zhang, R., Yang, X., Schmitt, D., et al. (2008). Relationship of paraoxonase 1 (PON1) gene polymorphisms and functional activity with systemic oxidative stress and cardiovascular risk. JAMA 299, 1265-1276. doi: 10.1001/jama.299.11.1265

Borup, A., Christensen, P. M., Nielsen, L. B., and Christoffersen, C. (2015). Apolipoprotein $\mathrm{M}$ in lipid metabolism and cardiometabolic diseases. Curr. Opin. Lipidol. 26, 48-55. doi: 10.1097/MOL.0000000000000142

Cherry, N., Mackness, M., Durrington, P., Povey, A., Dippnall, M., Smith, T., et al. (2002). Paraoxonase (PON1) polymorphisms in farmers attributing ill health to sheep dip. Lancet 359, 763-764. doi: 10.1016/S0140-6736(02) 07847-9

Christison, J. K., Rye, K. A., and Stocker, R. (1995). Exchange of oxidized cholesteryl linoleate between LDL and HDL mediated by cholesteryl ester transfer protein. J. Lipid Res. 36, 2017-2026.

Draganov, D. I., Teiber, J. F., Speelman, A., Osawa, Y., Sunahara, R., and La Du, B. N. (2005). Human paraoxonases (PON1, PON2, and PON3) are lactonases with overlapping and distinct substrate specificities. J. Lipid Res. 46, 1239-1247. doi: 10.1194/jlr.M400511-JLR200

Durrington, P. N., Mackness, B., and Mackness, M. I. (2001). Paraoxonase and atherosclerosis. Arterioscler. Thromb. Vasc. Biol. 21, 473-480. doi: 10.1161/01.ATV.21.4.473

Duverger, N., Kruth, H., Emmanuel, F., Caillaud, J. M., Viglietta, C., Castro, G., et al. (1996). Inhibition of atherosclerosis development in cholesterol-fed human apolipoprotein A-I-transgenic rabbits. Circulation 94, 713-717. doi: 10.1161/01.CIR.94.4.713

Elsøe, S., Ahnström, J., Christoffersen, C., Hoofnagle, A. N., Plomgaard, P., Heinecke, J. W., et al. (2012). Apolipoprotein M binds oxidized phospholipids and increases the antioxidant effect of HDL. Atherosclerosis 221, 91-97. doi: 10.1016/j.atherosclerosis.2011.11.031

Haraguchi, Y., Toh, R., Hasokawa, M., Nakajima, H., Honjo, T., Otsui, K., et al. (2014). Serum myeloperoxidase/paraoxonase 1 ratio as potential indicator of

\section{Conclusion}

The capacity of HDL to protect LDL against oxidative modification is considerable, but its potential therapeutic use to prevent atherosclerosis is as yet unfulfilled. The interaction of lipids with apoAI in HDL provides a lipoprotein particle capable of acquiring potentially toxic lipids and holding them in an environment where they may be safely hydrolyzed and from which they may be released to the liver for elimination. PON1, PLA2, and LCAT are present at higher concentrations in small, dense, protein-rich HDL (Karlsson et al., 2015), and HDL particles are therefore heterogeneous in their anti-oxidative capacity. PON1 is likely to be critical to the antioxidative capacity of HDL, but is likely to require a lipid environment to support its activity. Separation of HDL from PON1 disrupts this and the necessary environment is only imperfectly present with the currently available water-soluble recombinant forms of PON1. Acting together on HDL, PON1, apoAI, apoM, and PLA2 in conjunction with CETP and other lipid transfer proteins probably create a system with both antioxidative and antiglycative properties (see Figure 1).

dysfunctional high-density lipoprotein and risk stratification in coronary artery disease. Atherosclerosis 234, 288-294. doi: 10.1016/j.atherosclerosis.2014.03.009 Harel, M., Aharoni, A., Gaidukov, L., Brumshtein, B., Khersonsky, O., Meged, R., et al. (2004). Structure and evolution of the serum paraoxonase family of detoxifying and anti-atherosclerotic enzymes. Nat. Struct. Mol. Biol. 11, 412-419. doi: 10.1038/nsmb767

Heart Protection Study Collaborative, G. (2002). MRC/BHF Heart Protection Study of antioxidant vitamin supplementation in 20,536 high-risk individuals: a randomised placebo-controlled trial. Lancet 360, 23-33. doi: 10.1016/S01406736(02)09328-5

Hegele, R. A., Connelly, P. W., Scherer, S. W., Hanley, A. J., Harris, S. B., Tsui, L. C., et al. (1997). Paraoxonase-2 gene (PON2) G148 variant associated with elevated fasting plasma glucose in noninsulin-dependent diabetes mellitus. J. Clin. Endocrinol. Metab. 82, 3373-3377. doi: 10.1210/jc.82.10.3373

Hofer, S. E., Bennetts, B., Chan, A. K., Holloway, B., Karschimkus, C., Jenkins, A. J., et al. (2006). Association between PON 1 polymorphisms, PON activity and diabetes complications. J. Diabetes Complicat. 20, 322-328. doi: 10.1016/j.jdiacomp.2005.08.008

Holleboom, A. G., Daniil, G., Fu, X., Zhang, R., Hovingh, G. K., Schimmel, A. W., et al. (2012). Lipid oxidation in carriers of lecithin:cholesterol acyltransferase gene mutations. Arterioscler. Thromb. Vasc. Biol. 32, 3066-3075. doi: 10.1161/ATVBAHA.112.255711

Huang, Y., Wu, Z., Riwanto, M., Gao, S., Levison, B. S., Gu, X., et al. (2013). Myeloperoxidase, paraoxonase-1, and HDL form a functional ternary complex. J. Clin. Invest. 123, 3815-3828. doi: 10.1172/JCI67478

Karlsson, H., Kontush, A., and James, R. W. (2015). Functionality of HDL: antioxidation and detoxifying effects. Handb. Exp. Pharmacol. 224, 207-228. doi: 10.1007/978-3-319-09665-0_5

Kontush, A., and Chapman, M. J. (2010). Antiatherogenic function of HDL particle subpopulations: focus on antioxidative activities. Curr. Opin. Lipidol. 21, 312-318. doi: 10.1097/MOL.0b013e32833bcdc1

Litvinov, D., Mahini, H., and Garelnabi, M. (2012). Antioxidant and antiinflammatory role of paraoxonase 1: implication in arteriosclerosis diseases. N. Am. J. Med. Sci. 4, 523-532. doi: 10.4103/1947-2714.103310

Mackness, B., Davies, G. K., Turkie, W., Lee, E., Roberts, D. H., Hill, E., et al. (2001). Paraoxonase status in coronary heart disease: are activity and concentration more important than genotype? Arterioscler. Thromb. Vasc. Biol. 21, 1451-1457. doi: 10.1161/hq0901.094247

Mackness, B., Durrington, P., McElduff, P., Yarnell, J., Azam, N., Watt, M., et al. (2003). Low paraoxonase activity predicts coronary events 
in the Caerphilly Prospective Study. Circulation 107, 2775-2779. doi: 10.1161/01.CIR.0000070954.00271.13

Mackness, B., Durrington, P. N., Abuashia, B., Boulton, A. J., and Mackness, M. I. (2000). Low paraoxonase activity in type II diabetes mellitus complicated by retinopathy. Clin. Sci. 98, 355-363. doi: 10.1042/cs0980355

Mackness, B., Durrington, P. N., Boulton, A. J., Hine, D., and Mackness, M. I. (2002). Serum paraoxonase activity in patients with type 1 diabetes compared to healthy controls. Eur. J. Clin. Invest. 32, 259-264. doi: 10.1046/j.13652362.2002.00977.x

Mackness, B., Durrington, P. N., and Mackness, M. I. (1998). Lack of protection against oxidative modification of LDL by avian HDL. Biochem. Biophys. Res. Commun. 247, 443-446. doi: 10.1006/bbrc.1998.8803

Mackness, M. I., Arrol, S., Abbott, C., and Durrington, P. N. (1993). Protection of low-density lipoprotein against oxidative modification by highdensity lipoprotein associated paraoxonase. Atherosclerosis 104, 129-135. doi: 10.1016/0021-9150(93)90183-U

Mackness, M. I., Arrol, S., and Durrington, P. N. (1991). Paraoxonase prevents accumulation of lipoperoxides in low-density lipoprotein. FEBS Lett. 286, 152-154. doi: 10.1016/0014-5793(91)80962-3

Mackness, M. I., Arrol, S., Mackness, B., and Durrington, P. N. (1997). Alloenzymes of paraoxonase and effectiveness of high-density lipoproteins in protecting low-density lipoprotein against lipid peroxidation. Lancet 349, 851-852. doi: 10.1016/S0140-6736(05)61755-2

McCully, K. S. (1993). Chemical pathology of homocysteine. I. Atherogenesis. Ann. Clin. Lab. Sci. 23, 477-493.

Mishra, V. K., Palgunachari, M. N., McPherson, D. T., and Anantharamaiah, G. M. (2013). Lipid complex of apolipoprotein A-I mimetic peptide $4 \mathrm{~F}$ is a novel platform for paraoxonase-1 binding and enhancing its activity and stability. Biochem. Biophys. Res. Commun. 430, 975-980. doi: 10.1016/j.bbrc.2012.11.128

Miyata, M., and Smith, J. D. (1996). Apolipoprotein E allele-specific antioxidant activity and effects on cytotoxicity by oxidative insults and beta-amyloid peptides. Nat. Genet. 14, 55-61. doi: 10.1038/ng0996-55

Parthasarathy, S., Barnett, J., and Fong, L. G. (1990). High-density lipoprotein inhibits the oxidative modification of low-density lipoprotein. Biochim. Biophys. Acta 1044, 275-283. doi: 10.1016/0005-2760(90)90314-N

Plump, A. S., Azrolan, N., Odaka, H., Wu, L., Jiang, X., Tall, A., et al. (1997). ApoA-I knockout mice: characterization of HDL metabolism in homozygotes and identification of a post-RNA mechanism of apoA-I up-regulation in heterozygotes. J. Lipid Res. 38, 1033-1047.

Rodrigo, L., Mackness, B., Durrington, P. N., Hernandez, A., and Mackness, M. I. (2001). Hydrolysis of platelet-activating factor by human serum paraoxonase. Biochem. J. 354(Pt 1), 1-7. doi: 10.1042/bj3540001

Rosenblat, M., Volkova, N., and Aviram, M. (2011). Injection of paraoxonase 1 (PON1) to mice stimulates their HDL and macrophage antiatherogenicity. Biofactors 37, 462-467. doi: 10.1002/biof.188

Rosenson, R. S., and Hurt-Camejo, E. (2012). Phospholipase A2 enzymes and the risk of atherosclerosis. Eur. Heart J. 33, 2899-2909. doi: 10.1093/eurheartj/ehs148

Rozenberg, O., Shiner, M., Aviram, M., and Hayek, T. (2008). Paraoxonase 1 (PON1) attenuates diabetes development in mice through its antioxidative properties. Free Radic. Biol. Med. 44, 1951-1959. doi: 10.1016/j.freeradbiomed.2008.02.012

Rye, K. A., and Barter, P. J. (2014). Cardioprotective functions of HDLs. J. Lipid Res. 55, 168-179. doi: 10.1194/jlr.R039297
Shih, D. M., Gu, L., Xia, Y. R., Navab, M., Li, W. F., Hama, S., et al. (1998). Mice lacking serum paraoxonase are susceptible to organophosphate toxicity and atherosclerosis. Nature 394, 284-287. doi: 10.1038/28406

Soran, H., Younis, N. N., Charlton-Menys, V., and Durrington, P. (2009). Variation in paraoxonase-1 activity and atherosclerosis. Curr. Opin. Lipidol. 20, 265-274. doi: 10.1097/MOL.0b013e32832ec141

Steinberg, D., and Witztum, J. L. (2010). Oxidized low-density lipoprotein and atherosclerosis. Arterioscler. Thromb. Vasc. Biol. 30, 2311-2316. doi: 10.1161/ATVBAHA.108.179697

Stocker, R., and Keaney, J. F. Jr. (2004). Role of oxidative modifications in atherosclerosis. Physiol. Rev. 84, 1381-1478. doi: 10.1152/physrev.00047.2003

Tames, F. J., Mackness, M. I., Arrol, S., Laing, I., and Durrington, P. N. (1992). Nonenzymatic glycation of apolipoprotein B in the sera of diabetic and non-diabetic subjects. Atherosclerosis 93, 237-244. doi: 10.1016/0021-9150(92)90260-N

Tward, A., Xia, Y. R., Wang, X. P., Shi, Y. S., Park, C., Castellani, L. W., et al. (2002). Decreased atherosclerotic lesion formation in human serum paraoxonase transgenic mice. Circulation 106, 484-490. doi: 10.1161/01.CIR.0000023623.87083.4F

Wang, J., Yang, M. M., Rong, S. S., Ng, T. K., Li, Y. B., and Liu, X. M. (2013). Association of paraoxonase gene polymorphisms with diabetic nephropathy and retinopathy. Mol. Med. Rep. 8, 1845-1851. doi: 10.3892/mmr.2013.1710

Wang, M., Lang, X., Cui, S., Zou, L., Cao, J., Wang, S., et al. (2012). Quantitative assessment of the influence of paraoxonase 1 activity and coronary heart disease risk. DNA Cell Biol. 31, 975-982. doi: 10.1089/dna.2011.1478

Wheeler, J. G., Keavney, B. D., Watkins, H., Collins, R., and Danesh, J. (2004). Four paraoxonase gene polymorphisms in 11212 cases of coronary heart disease and 12786 controls: meta-analysis of 43 studies. Lancet 363, 689-695. doi: 10.1016/S0140-6736(04)15642-0

Younis, N., Charlton-Menys, V., Sharma, R., Soran, H., and Durrington, P. N. (2009). Glycation of LDL in non-diabetic people: small dense LDL is preferentially glycated both in vivo and in vitro. Atherosclerosis 202, 162-168. doi: 10.1016/j.atherosclerosis.2008.04.036

Younis, N. N., Soran, H., Charlton-Menys, V., Sharma, R., Hama, S., Pemberton, P., et al. (2013). High-density lipoprotein impedes glycation of low-density lipoprotein. Diab. Vasc. Dis. Res. 10, 152-160. doi: 10.1177/1479164112454309

Younis, N. N., Soran, H., Sharma, R., Charlton-Menys, V., Greenstein, A., Elseweidy, M. M., et al. (2010). Small-dense LDL and LDL glycation in metabolic syndrome and in statin-treated and non-statin-treated type 2 diabetes. Diab. Vasc. Dis. Res. 7, 289-295. doi: 10.1177/1479164110383063

Zhang, C., Peng, W., Wang, M., Zhu, J., Zang, Y., Shi, W., et al. (2010). Studies on protective effects of human paraoxonases 1 and 3 on atherosclerosis in apolipoprotein E knockout mice. Gene Ther. 17, 626-633. doi: $10.1038 /$ gt.2010.11

Conflict of Interest Statement: The authors declare that the research was conducted in the absence of any commercial or financial relationships that could be construed as a potential conflict of interest.

Copyright (c) 2015 Soran, Schofield and Durrington. This is an open-access article distributed under the terms of the Creative Commons Attribution License (CC BY). The use, distribution or reproduction in other forums is permitted, provided the original author(s) or licensor are credited and that the original publication in this journal is cited, in accordance with accepted academic practice. No use, distribution or reproduction is permitted which does not comply with these terms. 